\title{
Methotrexate: Underused and ignored?
}

\author{
Hans H Herfarth, Millie D Long, and Kim L Isaacs \\ Division of Gastroenterology and Hepatology, University of North Carolina
}

\begin{abstract}
For greater than a decade, methotrexate has been known to be an effective therapeutic agent in the treatment of steroid dependent active Crohn's disease. However, international data on medication utilization suggest that this drug is rarely used in clinical practice for an indication of Crohn's disease. This review investigates the potential reasons for the underuse of methotrexate in patients with inflammatory bowel diseases.
\end{abstract}

\section{Introduction}

Analyses of the volume of prescriptions for methotrexate reveal that methotrexate is prescribed in a negligible quantity when compared to other drugs used in the treatment of inflammatory bowel diseases (IBD), such as biologic anti-tumor necrosis factor-alpha (antiTNF) agents or thiopurines. We used data from LifeLink ${ }^{\mathrm{TM}}$ Health Plan Claims Database (IMS Health, Norwalk, CT) from 1997 through 2009, to calculate the number of prescriptions per 100,000 person-months by year in a cohort of over 100,000 individuals with IBD. Methotrexate use was negligible when compared to other immunosuppressive medications (Figure 1). In international studies of medication utilization in pediatric and elderly populations, methotrexate utilization in IBD has also been shown to be lower than that of other medications, such as biologic anti-TNF agents. By comparison, Canadian methotrexate use is somewhat higher than that of other European countries and the US, but overall use remains low ${ }^{1-3}$. Yet, methotrexate, which was initially developed in 1948 for the treatment of leukemia, has a successful track record in the treatment of autoimmune and neoplastic diseases. Moreover, for nearly 60 years it has been used clinically as low and high dose therapy to treat lymphomas, Wegener's disease, psoriasis and rheumatoid arthritis. We will explore the possible rationale for low utilization of methotrexate in IBD, including effectiveness compared to other available drugs, toxicity, costs, patient preference and recommendations by current treatment guidelines.

\section{Efficacy of methotrexate in Crohn's disease and ulcerative colitis}

The clinical efficacy of methotrexate has been well established for steroid dependent Crohn's disease (CD) in adults. The first report by Kozarek et al. in 1989 described 21 patients (14 with CD, 7 with ulcerative colitis (UC)), who were treated with $25 \mathrm{mg}$ methotrexate intramuscularly (im) ${ }^{4}$. The outcome of this "therapeutic experiment" was very

Correspondence to: Hans Herfarth, MD, PhD, Division of Gastroenterology and Hepatology, Department of Medicine, University of North Carolina, Bioinformatics Bldg., CB\#7080, Chapel Hill, NC, 27599, USA, hherf@ med.unc.edu. 
encouraging with the majority of the patients (16 of the 21) reporting improvement of their symptoms. Based on this initial experience the North American Crohn's study group performed a landmark trial in patients with steroid dependent $\mathrm{CD}$. At the end of 16 weeks significantly more patients receiving methotrexate $(25 \mathrm{mg}$ im /week) were in clinical remission compared to patients treated with placebo (39\% vs $19 \%, \mathrm{p}<0.03)^{5}$. To compensate for the delayed onset of action of methotrexate of 6-8 weeks all patients in the trial underwent a 12-week steroid-tapering schedule. Sixty-five $\%$ of the patients, who entered remission after 16 to 24 weeks of treatment with methotrexate $(25 \mathrm{mg} / \mathrm{im} / \mathrm{once}$ weekly), stayed in remission on $15 \mathrm{mg}$ / im /once weekly for over 40 weeks compared to $39 \%$ on placebo $(\mathrm{p}<0.04)^{6}$. Subsequently several uncontrolled observations in adults and children similarly reported the effectiveness of methotrexate in CD patients, who did not respond or did not tolerate thiopurines ${ }^{7-10}$. Methotrexate also seems to have some efficacy in treating fistulizing Crohn's disease ${ }^{9,11}$.

Conversely, there were also two smaller placebo controlled trials published in 1997 and 1999 after the initial successful North American Crohn's study group trial (2 and 4 years respectively), which failed to show any significant effectiveness of methotrexate compared to placebo ${ }^{12,13}$. These 2 studies may serve as prime examples of factors that can potentially influence methotrexate effectiveness in patients with IBD, including dosing and method of application. Both studies used oral methotrexate at doses of either $12.5 \mathrm{mg}$ once weekly or $15 \mathrm{mg}$ once weekly. Knowledge of a dose-response for methotrexate therapy is well established in rheumatoid arthritis (RA), psoriasis and also in a small trial of IBD patients, demonstrating that higher doses of around $25 \mathrm{mg}$ once weekly may be essential to control the inflammatory activity in patients with IBD ${ }^{14-18}$.

Methotrexate, if given orally, is absorbed in the proximal jejunum. The exact process of absorption is not yet elucidated. Thus, in patients with small bowel $\mathrm{CD}$, absorption and the ensuing bioavailability of methotrexate may be reduced. Oral methotrexate most likely reaches sufficient bioavailability at a dose below $15 \mathrm{mg}$, however above this threshold absorption rates and thus the bioavailability can decrease by $30 \%-70 \% 19-22$. The difference between oral and subcutaneous (sc) application with regard to clinical effectiveness has been elegantly demonstrated in a study by Braun et al, which confirmed a significantly higher efficacy of $15 \mathrm{mg}$ methotrexate when applied as an sc injection once weekly than to the same dose taken orally once weekly 23 .

The clinical value of methotrexate in UC is currently being debated. The only prospective placebo controlled trial in patients with steroid dependent UC did not reveal significant differences in the clinical outcome between oral methotrexate $(12.5 \mathrm{mg} /$ week $)$ and placebo ${ }^{24}$. However, several case series suggest that methotrexate could be similarly effective in patients with UC as in CD if methotrexate is administered by a method (sc or im) and dosage ( $25 \mathrm{mg} /$ week) analogous to that utilized in the North American Crohn's study (reviewed by Herfarth et al in 2010 and Carbonnel in 2011 25, 26).

Two clinical trials are underway to finally prove or refute the efficacy of methotrexate in UC. An investigator-initiated trial in France titled "Comparison of Methotrexate vs Placebo in Steroid-Refractory Ulcerative Colitis (acronym: METEOR)“ is currently investigating the 
effectiveness of methotrexate ( $25 \mathrm{mg} / \mathrm{week} / \mathrm{sc}$ ) compared to placebo in inducing steroid-free remission in steroid-dependent ulcerative colitis (www.ClinicalTrials.gov; NCT00498589). The second clinical trial started in February 2012 and is recruiting patients in the US (figure 2). This randomized, double blind, prospective trial (MEthotrexate Response In Treatment of Ulcerative Colitis; acronym: Merit-UC) investigates the ability of methotrexate to induce and maintain steroid-free remission in patients with UC (www.ClinicalTrials.gov;

NCT01393405). Hopefully both of these trials will help to further elucidate the efficacy of methotrexate in patients with active UC in need for an effective and affordable steroidsparing agent.

\section{Efficacy of methotrexate compared to azathioprine}

Cochrane analyses pertaining to the ability of azathioprine/6-mercaptopurine (6-MP) or methotrexate in inducing and maintaining remission in patients with steroid-dependent CD reveal similar efficacies for both therapies for the number of patients needed to be treated to achieve and maintain remission (table 1) ${ }^{27-30}$. Only a few small direct comparative studies exist in IBD aiming to compare the clinical value of methotrexate with that of azathioprine or 6-MP. In a study by Mate-Jimenez et al., which included steroid-dependent patients with $\mathrm{CD}(\mathrm{n}=34)$ or ulcerative colitis $(\mathrm{n}=38), 79 \%$ of patients randomized to $6-\mathrm{MP}(1.5 \mathrm{mg} / \mathrm{kg}$ day $)$ were in remission after 30 weeks compared to $58 \%$ of patients on methotrexate $(15 \mathrm{mg} / \mathrm{week} /$ oral) ${ }^{31}$. No significant differences in the rate of remission and steroid sparing were found in patients with steroid-dependent $\mathrm{CD}(\mathrm{n}=54)$ assigned either to methotrexate or azathioprine (figure 3$)^{32}$. An Israeli multicenter trial comparing the efficacy of $12.5 \mathrm{mg}$ methotrexate $(\mathrm{n}=26), 50 \mathrm{mg}$ 6-MP $(\mathrm{n}=32)$ or placebo $(\mathrm{n}=26)$ in patients with steroid-dependent CD over a 9 months period found that neither treatment was better than placebo ${ }^{13}$. However, in this trial neither methotrexate nor 6-MP were given in an optimal dose or route of administration.

\section{Toxicity - adverse effects (AE) of methotrexate therapy}

AE's of low-dose methotrexate therapy most often affect the gastrointestinal tract and include nausea, anorexia and less often stomatitis or diarrhea. More serious AE's include hepatotoxicity, bone marrow suppression ${ }^{33}$ and rarely hypersensitivity pneumonitis and opportunistic infections can occur ${ }^{34}$. Since the majority of the drug is eliminated unchanged via the kidneys, toxicity of methotrexate in patients with impaired kidney function or dehydration is increased ${ }^{35}$. Of note, so far no increased risk for lymphoma or other neoplasms has been described in patients on long-term methotrexate therapy 36,37 .

One major concern is the development of liver fibrosis and cirrhosis. Known factors associated with hepatotoxicity in patients treated with methotrexate are alcohol consumption, obesity, diabetes mellitus and viral hepatitis ${ }^{36,38}$. However, the overall perception of an increased risk of liver cirrhosis due to methotrexate therapy is probably based on the reported high incidences (greater than 20\%) of liver fibrosis and cirrhosis in patients with psoriasis on methotrexate therapy ${ }^{39}$. The exact mechanism for this high rate is not completely clarified, but one major factor of methotrexate-induced hepatotoxicity, aside the above-mentioned comorbidities, is the frequency of administration ${ }^{40}$. Low dosages 
given daily or on alternate days, as was initially performed in patients with psoriasis, results in a significant increase in the incidence of fibrosis or cirrhosis compared to larger doses given once weekly. This is probably due to an increased accumulation of toxic methotrexate metabolites in the liver, which most likely are insufficiently cleared with more frequent drug administration. In the setting of once weekly administrations the overall incidence of liver fibrosis seems to be very low in patients with rheumatoid arthritis and IBD. Kremer reports only 2 cases of liver cirrhosis in 719 patients with rheumatoid arthritis undergoing liver biopsies ${ }^{41}$. Several studies in patients with IBD with cumulative dosages of methotrexate of up to 2.5 gram did not demonstrate liver cirrhosis on biopsy $8,42-44$.

A more common AE is the elevation of the liver enzymes aspartate transaminase (AST) and/or alanine transaminase (ALT). In the initial trial in patients with steroid-dependent CD, the elevation of these liver enzymes led to the withdrawal of 7\% (7/94) of patients in the first 16 weeks of therapy with $25 \mathrm{mg}$ methotrexate/week/im. ${ }^{5}$. In the long-term study with maintenance therapy of $15 \mathrm{mg}$ methotrexate/week/im no further patients had to be withdrawn because of liver toxicity ${ }^{6}$.

The occurrence of drug-associated AE leading to the withdrawal of patients in the head to head trials of azathioprine/6-MP and methotrexate appears to be similar. In the largest trial by Ardizzone et al., $11 \%$ (6/54) of patients treated with azathioprine $2 \mathrm{mg} / \mathrm{kg} /$ day for 6 months or $25 \mathrm{mg}$ methotrexate/week (initially intravenous for 3 months, then oral application $)^{32}$ had to be withdrawn from drug treatment due to a drug associated AE. Reasons for withdrawal in the azathioprine group were fever, pancreatitis or hepatitis. For the methotrexate group, withdrawals occurred due to thrombocytopenia, leukopenia and hepatitis.

\section{Cost and patient preference}

Known drug adverse effects, clinical effectiveness and drug-associated costs drive patient's therapy preferences. Methotrexate is one of the most affordable immunosuppressive drugs in the current armamentarium of IBD therapy ${ }^{45}, 46$. Even taking into account the generally recommended repeated measurements of CBC and LFTs every 4-8 weeks, it is highly cost effective. However, due to the need for weekly self-injections, patients might object to methotrexate if given a choice of an oral medication such as azathioprine compared to the injection with methotrexate (figure 4) ${ }^{47}$. Additionally the need for vigorous birth control due to the teratogenicity of methotrexate might deter younger female patients. In fact methotrexate is the only drug with an absolute contraindication for pregnancy and breastfeeding compared to all other medications used in IBD ${ }^{48}$. Of note, a multi-national evidence based recommendation on the use of methotrexate in rheumatic disorders currently counsels also male patients that methotrexate therapy should be stopped 3 months before a planned pregnancy ${ }^{14}$. This advice is based mainly on expert opinion and not on reliable clinical data. There are controversial reports of sterility in males on methotrexate mostly in the setting of chemotherapy, but there are no available studies, which evaluated the effect of methotrexate for men on miscarriages/birth defects or on newborns ${ }^{49}$. 


\section{Guideline recommendations}

In Europe, methotrexate is recommended as a second or third line immunosuppressive regimen in the current treatment guidelines ${ }^{50}$. The guidelines currently state "...but at present, methotrexate is generally reserved for treatment of active or relapsing $\mathrm{CD}$ in those refractory to or intolerant of thiopurines or anti-TNF agents." This recommendation is interesting, since the use of methotrexate in this scenario has not been evaluated in prospective clinical trials. Treatment recommendations from the US do not explicitly advise a preference for azathioprine/6-MP over methotrexate, rather acknowledge that more dose ranging and maintenance studies for methotrexate are needed ${ }^{51,52}$.

\section{Conclusion}

In summary, there are several potential reasons why methotrexate is used with such a low frequency in the treatment of IBD (table 2). However, given its proven clinical efficacy in $\mathrm{CD}$, methotrexate remains an affordable alternative. Methotrexate use should be considered for therapy of $\mathrm{CD}$, particularly given the current climate of rising health care costs.

\section{Acknowledgements}

Drs. Herfarth and Isaacs are supported by the National Institutes of Health (1U01DK092239-01). Dr. Long is supported by a junior faculty career development award from the Crohn's and Colitis Foundation of America.

The statements, findings, conclusions, views, and opinions contained and expressed in this article are based in part on data obtained under license from the following IMS Health Incorporated information service(s): IMS LifeLink ${ }^{\mathrm{TM}}$ Health Plan Claims Database (Start Year-End Year3), IMS Health Incorporated. All Rights Reserved. The statements, findings, conclusions, views, and opinions contained and expressed herein are not necessarily those of IMS Health Incorporated or any of its affiliated or subsidiary entities.

\section{References}

1. Benchimol EI, Cook S, Erichsen R, et al. Su1010 International Variation in Medication Prescription Rates in Elderly Patients With Inflammatory Bowel Disease. Gastroenterology. 2012; 142:S-398S-399.

2. Benchimol EI, Erichsen R, Cook S, et al. 1146 International Variation in Medication Prescription Rates in Children With Inflammatory Bowel Disease. Gastroenterology. 2012; 142:S-208.

3. Saibeni S, Bollani S, Losco A, et al. The use of methotrexate for treatment of inflammatory bowel disease in clinical practice. Dig Liver Dis. 2012; 44:123-7. [PubMed: 22051323]

4. Kozarek RA, Patterson DJ, Gelfand MD, et al. Methotrexate induces clinical and histologic remission in patients with refractory inflammatory bowel disease. Ann Intern Med. 1989; 110:3536. [PubMed: 2492786]

5. Feagan BG, Rochon J, Fedorak RN, et al. Methotrexate for the treatment of Crohn's disease. The North American Crohn's Study Group Investigators. N Engl J Med. 1995; 332:292-7. [PubMed: 7816064]

6. Feagan BG, Fedorak RN, Irvine EJ, et al. A comparison of methotrexate with placebo for the maintenance of remission in Crohn's disease. North American Crohn's Study Group Investigators. N Engl J Med. 2000; 342:1627-32. [PubMed: 10833208]

7. Vandeputte L, D'Haens G, Baert F, et al. Methotrexate in refractory Crohn's disease. Inflamm Bowel Dis. 1999; 5:11-5. [PubMed: 10028444]

8. Lemann M, Zenjari T, Bouhnik Y, et al. Methotrexate in Crohn's disease: long-term efficacy and toxicity. Am J Gastroenterol. 2000; 95:1730-4. [PubMed: 10925976]

Dig Dis. Author manuscript; available in PMC 2015 November 02. 
9. Turner D, Grossman AB, Rosh J, et al. Methotrexate following unsuccessful thiopurine therapy in pediatric Crohn's disease. Am J Gastroenterol. 2007; 102:2804-12. quiz 2803, 2813. [PubMed: 18042110]

10. Lemann M, Chamiot-Prieur C, Mesnard B, et al. Methotrexate for the treatment of refractory Crohn's disease. Aliment Pharmacol Ther. 1996; 10:309-14. [PubMed: 8791956]

11. Mahadevan U, Marion JF, Present DH. Fistula response to methotrexate in Crohn's disease: a case series. Aliment Pharmacol Ther. 2003; 18:1003-8. [PubMed: 14616166]

12. Arora S, Katkov W, Cooley J, et al. Methotrexate in Crohn's disease: results of a randomized, double-blind, placebo-controlled trial. Hepatogastroenterology. 1999; 46:1724-9. [PubMed: 10430331]

13. Oren R, Moshkowitz M, Odes S, et al. Methotrexate in chronic active Crohn's disease: a doubleblind, randomized, Israeli multicenter trial. Am J Gastroenterol. 1997; 92:2203-9. [PubMed: 9399753]

14. Visser K, Katchamart W, Loza E, et al. Multinational evidence-based recommendations for the use of methotrexate in rheumatic disorders with a focus on rheumatoid arthritis: integrating systematic literature research and expert opinion of a broad international panel of rheumatologists in the $3 \mathrm{E}$ Initiative. Ann Rheum Dis. 2009; 68:1086-93. [PubMed: 19033291]

15. Visser K, van der Heijde D. Optimal dosage and route of administration of methotrexate in rheumatoid arthritis: a systematic review of the literature. Ann Rheum Dis. 2009; 68:1094-9. [PubMed: 19033290]

16. Egan LJ, Sandborn WJ, Tremaine WJ, et al. A randomized dose-response and pharmacokinetic study of methotrexate for refractory inflammatory Crohn's disease and ulcerative colitis. Aliment Pharmacol Ther. 1999; 13:1597-604. [PubMed: 10594394]

17. Seideman P. Methotrexate-the relationship between dose and clinical effect. Rheumatology. $1993 ; 32: 751-753$.

18. Montaudie H, Sbidian E, Paul C, et al. Methotrexate in psoriasis: a systematic review of treatment modalities, incidence, risk factors and monitoring of liver toxicity. J Eur Acad Dermatol Venereol. 2011; 25(Suppl 2):12-8. [PubMed: 21388454]

19. Hamilton RA, Kremer JM. Why intramuscular methotrexate may be more efficacious than oral dosing in patients with rheumatoid arthritis. Br J Rheumatol. 1997; 36:86-90. [PubMed: 9117183]

20. Kurnik D, Loebstein R, Fishbein E, et al. Bioavailability of oral vs. subcutaneous low-dose methotrexate in patients with Crohn's disease. Aliment Pharmacol Ther. 2003; 18:57-63. [PubMed: 12848626]

21. Balis FM, Mirro J Jr. Reaman GH, et al. Pharmacokinetics of subcutaneous methotrexate. J Clin Oncol. 1988; 6:1882-6. [PubMed: 3199171]

22. Jundt JW, Browne BA, Fiocco GP, et al. A comparison of low dose methotrexate bioavailability: oral solution, oral tablet, subcutaneous and intramuscular dosing. J Rheumatol. 1993; 20:1845-9. [PubMed: 8308768]

23. Braun J, Kastner P, Flaxenberg P, et al. Comparison of the clinical efficacy and safety of subcutaneous versus oral administration of methotrexate in patients with active rheumatoid arthritis: results of a six-month, multicenter, randomized, double-blind, controlled, phase IV trial. Arthritis Rheum. 2008; 58:73-81. [PubMed: 18163521]

24. Oren R, Arber N, Odes S, et al. Methotrexate in chronic active ulcerative colitis: a double-blind, randomized, Israeli multicenter trial. Gastroenterology. 1996; 110:1416-21. [PubMed: 8613046]

25. Herfarth HH, Osterman MT, Isaacs KL, et al. Efficacy of methotrexate in ulcerative colitis: Failure or promise. Inflamm Bowel Dis. 2010; 16:1421-30. [PubMed: 20186931]

26. Carbonnel F. Methotrexate: a drug of the future in ulcerative colitis? Curr Drug Targets. 2011; 12:1413-6. [PubMed: 21466494]

27. Alfadhli AA, McDonald JW, Feagan BG. Methotrexate for induction of remission in refractory Crohn's disease. Cochrane Database Syst Rev. 2005:CD003459. [PubMed: 15674908]

28. Patel V, Macdonald JK, McDonald JW, et al. Methotrexate for maintenance of remission in Crohn's disease. Cochrane Database Syst Rev. 2009:CD006884. [PubMed: 19821390] 
29. Prefontaine E, Sutherland LR, Macdonald JK, et al. Azathioprine or 6-mercaptopurine for maintenance of remission in Crohn's disease. Cochrane Database Syst Rev. 2009:CD000067. [PubMed: 19160175]

30. Prefontaine E, Macdonald JK, Sutherland LR. Azathioprine or 6-mercaptopurine for induction of remission in Crohn's disease. Cochrane Database Syst Rev. 2010:CD000545. [PubMed: 20556747]

31. Mate-Jimenez J, Hermida C, Cantero-Perona J, et al. 6-mercaptopurine or methotrexate added to prednisone induces and maintains remission in steroid-dependent inflammatory bowel disease. Eur J Gastroenterol Hepatol. 2000; 12:1227-33. [PubMed: 11111780]

32. Ardizzone S, Bollani S, Manzionna G, et al. Comparison between methotrexate and azathioprine in the treatment of chronic active Crohn's disease: a randomised, investigator-blind study. Dig Liver Dis. 2003; 35:619-27. [PubMed: 14563183]

33. Stein RB, Hanauer SB. Comparative tolerability of treatments for inflammatory bowel disease. Drug Saf. 2000; 23:429-48. [PubMed: 11085348]

34. Searles G, McKendry RJ. Methotrexate pneumonitis in rheumatoid arthritis: potential risk factors. Four case reports and a review of the literature. J Rheumatol. 1987; 14:1164-71. [PubMed: 3325643]

35. The effect of age and renal function on the efficacy and toxicity of methotrexate in rheumatoid arthritis. Rheumatoid Arthritis Clinical Trial Archive Group. J Rheumatol. 1995; 22:218-23. [PubMed: 7738941]

36. Salliot C, van der Heijde D. Long-term safety of methotrexate monotherapy in patients with rheumatoid arthritis: a systematic literature research. Ann Rheum Dis. 2009; 68:1100-4. [PubMed: 19060002]

37. Wolfe F, Michaud K. Lymphoma in rheumatoid arthritis: the effect of methotrexate and anti-tumor necrosis factor therapy in 18,572 patients. Arthritis Rheum. 2004; 50:1740-51. [PubMed: 15188349]

38. Lindsay K, Fraser AD, Layton A, et al. Liver fibrosis in patients with psoriasis and psoriatic arthritis on long-term, high cumulative dose methotrexate therapy. Rheumatology (Oxford). 2009; 48:569-72. [PubMed: 19273538]

39. Kalb RE, Strober B, Weinstein G, et al. Methotrexate and psoriasis: 2009 National Psoriasis Foundation Consensus Conference. J Am Acad Dermatol. 2009; 60:824-37. [PubMed: 19389524]

40. Thomas JA, Aithal GP. Monitoring liver function during methotrexate therapy for psoriasis: are routine biopsies really necessary? Am J Clin Dermatol. 2005; 6:357-63. [PubMed: 16343024]

41. Kremer JM, Alarcon GS, Lightfoot RW Jr. et al. Methotrexate for rheumatoid arthritis. Suggested guidelines for monitoring liver toxicity. American College of Rheumatology. Arthritis Rheum. 1994; 37:316-28. [PubMed: 8129787]

42. Te HS, Schiano TD, Kuan SF, et al. Hepatic effects of long-term methotrexate use in the treatment of inflammatory bowel disease. Am J Gastroenterol. 2000; 95:3150-6. [PubMed: 11095334]

43. Fraser AG, Morton D, McGovern D, et al. The efficacy of methotrexate for maintaining remission in inflammatory bowel disease. Aliment Pharmacol Ther. 2002; 16:693-7. [PubMed: 11929386]

44. Fournier MR, Klein J, Minuk GY, et al. Changes in Liver Biochemistry During Methotrexate Use for Inflammatory Bowel Disease. Am J Gastroenterol. 2010

45. Kozarek RA. Long-term treatment of Crohn's disease with methotrexate, or, why's a nice drug like you still a wannabe in the treatment of inflammatory bowel disease? Am J Gastroenterol. 2000; 95:1619-20. [PubMed: 10925959]

46. Kappelman MD, Rifas-Shiman SL, Porter CQ, et al. Direct health care costs of Crohn's disease and ulcerative colitis in US children and adults. Gastroenterology. 2008; 135:1907-13. [PubMed: 18854185]

47. Fallowfield L, Atkins L, Catt S, et al. Patients' preference for administration of endocrine treatments by injection or tablets: results from a study of women with breast cancer. Ann Oncol. 2006; 17:205-10. [PubMed: 16239231]

48. Dubinsky M, Abraham B, Mahadevan U. Management of the pregnant IBD patient. Inflamm Bowel Dis. 2008; 14:1736-50. [PubMed: 18626967] 
49. French AE, Koren G. Effect of methotrexate on male fertility. Can Fam Physician. 2003; 49:5778. [PubMed: 12790266]

50. Dignass A, Assche GV, Lindsay JO, et al. The second European evidence-based Consensus on the diagnosis and management of Crohn's disease: Current management. 2010; 4:28-62.

51. Lichtenstein GR, Abreu MT, Cohen R, et al. American Gastroenterological Association Institute Technical Review on Corticosteroids, Immunomodulators, and Infliximab in Inflammatory Bowel Disease. Gastroenterology. 2006; 130:940-987. [PubMed: 16530532]

52. Lichtenstein GR, Hanauer SB, Sandborn WJ. Management of Crohn's disease in adults. Am J Gastroenterol. 2009; 104:465-83. [PubMed: 19174807]

53. Long, MD.; Martin, C.; Pipkin, CA., et al. Gastroenterology. 2012. Risk of Melanoma and NonMelanoma Skin Cancer among Patients with Inflammatory Bowel Disease. in press

Dig Dis. Author manuscript; available in PMC 2015 November 02. 


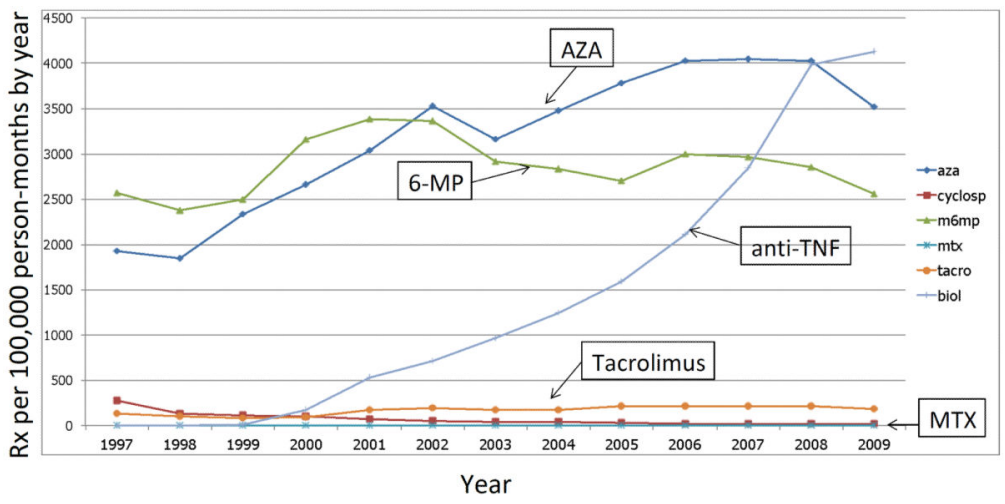

Figure 1.

Medication use in a cohort of 108,518 IBD patients between 1997 and 2009 in the USA. Source: IMS Health, LifeLink ${ }^{\mathrm{TM}}$ Health Plan Claims Database, From 1997 to 2009. Rx, prescription. For methods see ${ }^{53}$. 


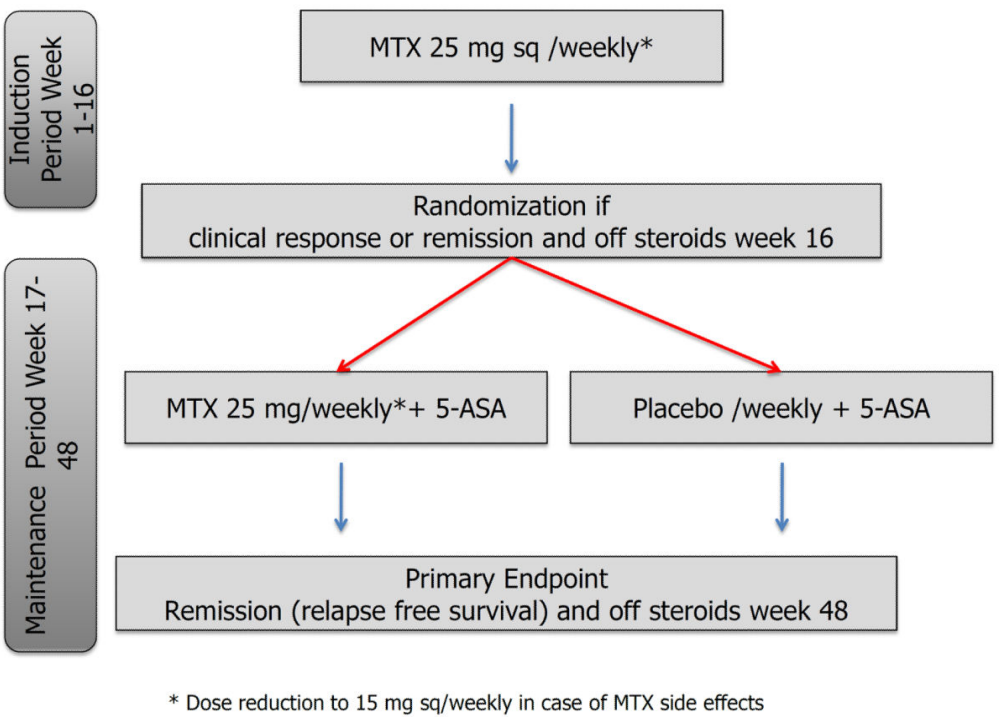

Figure 2.

Study flow of the randomized, double blind, prospective trial investigating the efficacy of methotrexate in induction and maintenance of steroid free remission in ulcerative colitis (MEthotrexate Response In Treatment of UC - MERIT-UC). 

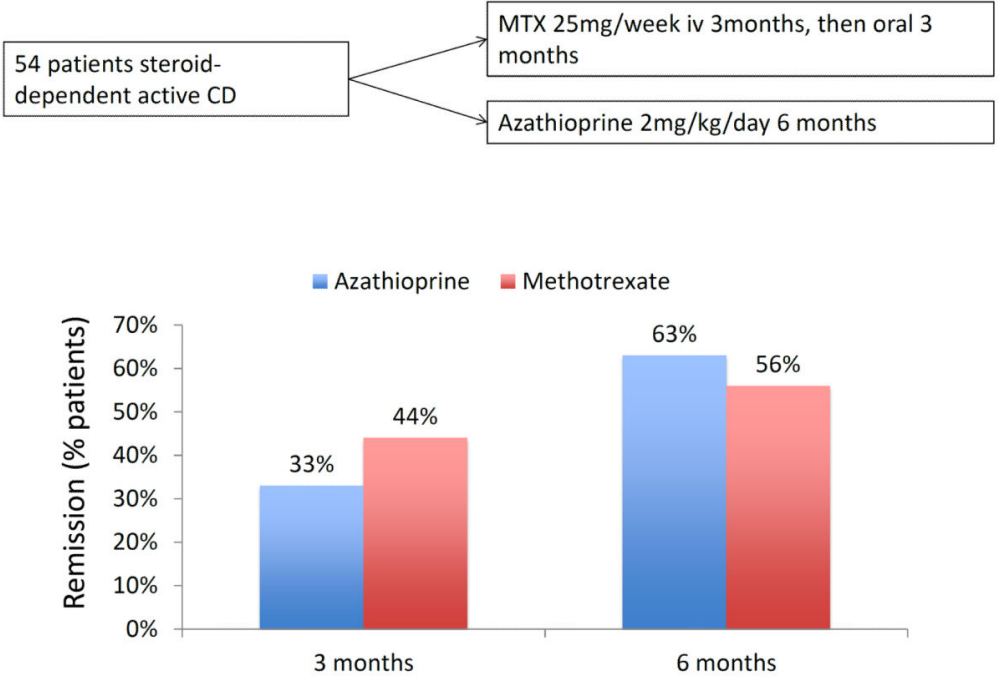

Figure 3.

Randomized, investigator-blind study investigating the therapeutic efficacy of methotrexate $25 \mathrm{mg} /$ week given initially intravenously (iv) for 3 months and then orally 3 for 3 months compared to azathioprine $2 \mathrm{mg} / \mathrm{kg}$ bodyweight/day ${ }^{32}$. 


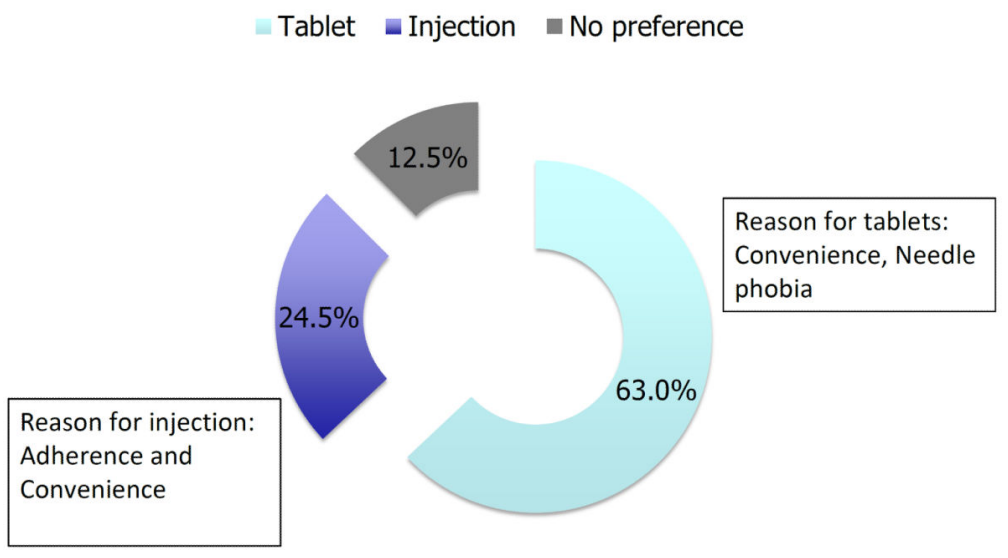

Figure 4.

Patient preference for administration of hormonal therapy with similar efficacy and tolerability of oral or subcutaneous application. The majority of 208 breast cancer patients preferred hormone therapy via daily tablets rather than monthly injections ${ }^{47}$. 
Table 1

Cochrane analyses of the efficacy of azathioprine (AZA) / 6-mercaptopurine (6-MP) and methotrexate (MTX). NNT: Number needed to treat, NNH: Number needed to harm. NR: not reported. ${ }^{27-30}$

\begin{tabular}{|l|c|c|c|c|}
\hline & Number of trials & Patients (drug+placebo) & NNT & NNH \\
\hline AZA/6-MP Induction & 8 & 425 & 5 & 14 \\
\hline MTX Induction & 1 & 141 & 5 & NR \\
\hline AZA/6-MP Maintenance & $7 / 1$ & 550 & $6 / 4$ & 20 \\
\hline MTX Maintenance & 3 & 98 & 4 & NR \\
\hline
\end{tabular}


Table 2

Potential factors influencing the use of methotrexate compared to other therapies in patients with IBD.

\begin{tabular}{|c|c|c|}
\hline Positive & Probably neither positive nor negative & Negative \\
\hline $\begin{array}{l}\text { - Maintenance of remission } \\
\text { in CD }\end{array}$ & - Effective to induce remission (with steroids) in CD & - Prior negative studies in UC \\
\hline - Inexpensive & - Toxicity (liver, lung, hematopoetic system) & - Needs to be injected \\
\hline \multirow[t]{2}{*}{$\begin{array}{l}\text { - No increased lymphoma } \\
\text { risk }\end{array}$} & $\begin{array}{l}\text { - Drug monitoring: No test to predict toxicity or } \\
\text { therapeutic levels }\end{array}$ & - Not to be used in case of anticipated pregnancy \\
\hline & • Fewer studies & $\begin{array}{l}\text { - Second/Third line recommendation (ECCO- } \\
\text { guidelines) }\end{array}$ \\
\hline
\end{tabular}

